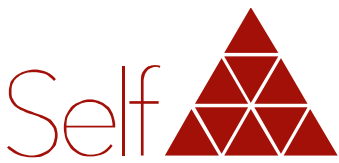

Revista do Instituto Junguiano de Săo Paulo

\title{
Abordagem clínica dos temas "morte" e "suicídio" na perspectiva da psicologia arquetípica
}

\author{
Helton Marculino de SOUZA \\ Lunalva Fiuza CHAGAS \\ Campinas/SP, Brasil.
}

Conflito de interesses:

Os autores declaram não haver nenhum interesse profissional ou pessoal que possa gerar conflito de interesses em relação a este manuscrito.

\section{Resumo}

A psicologia arquetípica se configura como uma abordagem criada a partir da psicologia analítica de C. G. Jung, tendo James Hillman como um de seus expoentes. $\bigcirc$ autor tem uma vasta obra que aborda temas diversos, dentre eles a morte e o suicídio. Tendo em vista a importância que estes dois temas apresentam no campo clínico, objetiva-se, por meio desta pesquisa, debater apontamentos teóricos, visando uma primeira sistematização sobre intervenções clínicas para abordagem de aspectos concernentes à morte e ao suicídio a partir de uma visão da psicologia arquetípica. Configura-se, metodologicamente, como uma pesquisa teórica empreendida por meio da consulta a obras de J. Hillman relativas aos temas elencados. Através desse estudo pode-se apreender que é de grande importância que o psicólogo entre em contato com temas relacionados à morte e ao suicídio, para que seja capaz de oferecer um acolhimento que não se limita a patologizar, mas a encarar a psique como entidade autônoma a priori, ou seja, fazer alma, como propõe Hillman, é estar disposto a se relacionar com o fenômeno que se apresenta, ao invés de interpretá-lo; conhecer as próprias fantasias e afetos ligados ao tema é indispensável ao psicólogo, para que o processo terapêutico frente a essa demanda seja possível.

\section{Descritores}

arquétipos, psicologia clínica, morte, suicídio. 


\title{
Clinical approach of the themes "death" and "suicide" from the perspective of archetypal psychology
}

\begin{abstract}
Archetypal psychology is configured as a theoretical approach created from C.G. Jung analytical psychology, with James Hillman as one of its exponents. The author has a vast body of work that addresses diverse topics, among them death and suicide. Considering the importance of these two themes in the clinical sphere, this research is intended to discuss theoretical notes, aiming at a first systematization on clinical interventions to approach aspects concerning death and suicide from the point of view Archetypal Psychology. It is methodologically defined as a theoretical research, undertaken through the consultation of works by J. Hillman on the topics listed. Through this study, the great importance of the psychologist coming into contact with issues related to death and suicide can be perceived, so that he is able to offer a welcoming response that is not limited to pathologizing but to view psyche as an a priori autonomous entity. Thus, soul-making, as proposed by Hillman, is to be willing to relate to the phenomenon that arises rather than interpreting it; it is indispensable to the psychologist to recognize own fantasies and affections related to the issue so that the therapeutic process be possible in face of this demand.
\end{abstract}

Descriptors

archetypes, clinical psychology, death and dying, suicide.

\section{Enfoque clínico de los temas "muerte" y "suicidio" en la perspectiva de la psicología arquetipal}

\section{Resumen}

La psicología arquetípica se configura como un abordaje teórico creado a partir de la psicología analítica de C. G. Jung, teniendo a James Hillman como uno de sus exponentes. El autor tiene una vasta obra que aborda temas diversos, entre ellos la muerte y el suicidio. Teniendo en cuenta la importancia que estos dos temas presentan en el campo clínico, esta investigación tiene el objetivo de debatir apuntes teóricos, buscando una primera sistematización de intervenciones clínicas para abordaje de aspectos concernientes a la muerte y al suicidio a partir de una visión de la Psicología 
Arquetípica. Metodológicamente, ella se configura como una investigación teórica, emprendida por medio de la consulta a obras de J. Hillman relativas a los temas enumerados. A través de este estudio, se puede percibir que es de gran importancia que el psicólogo entre en contacto con temas relacionados a la muerte y al suicidio para que sea capaz de ofrecer una acogida que no se limita a patologizar, sino a encarar a la psique como entidad autónoma a priori. Así, hacer alma, como propone Hillman, es estar dispuesto a relacionarse con el fenómeno que se presenta en vez de interpretarlo; conocer las propias fantasías y afectos vinculados al tema le es indispensable al psicólogo para que el proceso terapéutico sea posible frente esta demanda.

\section{Descriptores}

arquetipos, psicología clínica, muerte, suicidio. 


\section{Psicologia analítica e psicologia arquetípica: apontamentos iniciais}

Entre 1909 e 1912, Carl Gustav Jung viu-se frente a impasses com a psicanálise, levando-o ao rompimento com Freud e a uma jornada rumo a nova abordagem. Jung preocupava-se com a continuidade dos estudos para além de discípulos que apenas repetissem suas teorias: "Só espero e desejo que ninguém se torne junguiano. Eu não represento nenhuma doutrina, mas descrevo fatos e apresento certos pontos de vista que julgo merecedores de discussão" (Jung, 1976/2002, p. 9). Contudo, Jung tinha consciência do papel paternal que ocupava na fundamentação da psicologia analítica (Fordham, 1975, citado por Samuels, 1989).

Samuels (1989) discorreu sobre conceitos de Jung, bem como sobre autores pós-junguianos. Tal autor indica que há uma divisão das vertentes existentes atualmente em três grandes escolas: a escola clássica, de autores como Marie-Louise Von Franz e Eric Neumann; a escola desenvolvimentista, com sua origem em Londres, com influência da psicanálise e voltada ao desenvolvimento humano, desde o nascimento até a fase adulta, de autores como Michael Fordham e Mario Jacoby; e, por fim, a escola arquetípica, fundada por James Hillman, que explora e dá destaque aos arquétipos no trabalho clínico e na pesquisa (Samuels, 1989).

Nas palavras de Samuels (1989), "pode ser lamentável que essas divisões existam, ou pode ser saudavelmente inevitável, mas elas não devem ser ignoradas" (p. 28).

É importante a identificação do profissional com a abordagem teórica que usa, para que esta faça sentido para o clínico e para o pesquisador, ofertando recursos que fundamentem a articulação entre o objeto de estudo e o discurso científico. No que se refere à psicologia arquetípica, ela foi fundada por James Hillman e outros junguianos contemporâneos a ele, em Zurique, entre o final da década de 1960 e início da década de 1970. Esta nova abordagem surgiu pela insatisfação com relação ao fato de muitos estudiosos do Instituto Jung apenas repetirem os conceitos e princípios junguianos, ao invés de apresentarem um olhar crítico. Neste sentido, Hillman entendia a psicologia arquetípica como uma abordagem e não como uma escola (Adams, 2002).

Na psicologia arquetípica compreende-se que, por meio das imagens arquetípicas, a psique faz alma. Para que a dimensão do fazer alma seja compreendida destaca-se, brevemente, alguns conceitos que se relacionam com o tema: imagem, alma, arquétipo, mito e a relação destes na prática clínica.

Sant'Anna (2001) argumenta que nesta vertente tem-se uma consideração do termo "imaginal" como resultante de uma:

[...] concepção segundo a qual as imagens são vistas não como representações, sinais, símbolos, alegorias ou comunicações, mas 
como fenômenos originais peculiares à psique. Ela propõe portanto [sic] um tratamento direto e vivencial da imagem segundo o qual a explicação ou a interpretação egóicas [sic] são substituídas pela vivência, pelo tratamento lúdico e pela conexão emocional (p. 96).

Em consonância, acredita-se ser possível que algumas experiências possam se conservar apenas no campo vivencial, sem uma integração mediada pelo ego. A alma teria como atividade básica a transformação de situações ocorridas em experiência, transformação esta promovida a partir das imagens e ideias (Sant'Anna, 2001).

Quanto à imagem, esta é entendida como uma expressão de totalidade, algo que observamos e com a qual participamos. Samuels (1988) aponta, a partir dos estudos de Jung, que a imagem possui um poder gerador, configurando-se como algo que compele, incita psiquicamente o outro. Indica que:

A imagem é sempre uma expressão da totalidade percebida e percebível, apreendida e apreensível, pelo indivíduo. Enquanto, sobretudo pelo fim de sua vida, Jung discriminava entre a imagem arquetípica e $o$ arquétipo per se, na prática são as imagens que excitam o observador (por exemplo, o sonhador) até o grau de ele ser capaz de incorporar ou compreender ou realizar (tornar consciente) o que ele percebe (Samuels, 1988, p. 97).

Destaca-se que a imagem arquetípica se configura como a via para observar o arquétipo, em direção àquilo que ele simboliza. Dessa forma, contém ou amplifica o símbolo. São assim manifestações diretas do arquétipo. Por isso que se faz a distinção entre arquétipo e arquétipo per se, de modo que o per se refere-se ao arquétipo em sua forma essencialmente pura. $\bigcirc$ arquétipo per se apresentar-se-ia como sua forma ainda incompreendida, ou não percebida pelo homem, apesar de atuante e presente por si só.

Compreendem-se os arquétipos como estruturas básicas da psique que se apresentam por meio da imagem arquetípica. Jung discorre sobre o conceito de arquétipo e indica que:

arquétipo é um elemento vazio e formal em si [...] uma possibilidade dada a priori da forma da sua representação. $\bigcirc$ que é herdado não são as idéias [sic], mas as formas, as quais sob esse aspecto particular correspondem aos instintos igualmente determinados por sua forma (Jung, 1976/2002, p. 91).

Nas palavras de Hillman (1991, p. 21), "arquetípico pertence a toda a cultura, a todas as formas de atividade humana".

Hillman (2010) revisa a psicologia em seu livro "Re-vendo a psicologia". Barcellos (2006) destaca a importância da sílaba "re" imaginada no campo clínico: 
Como já observou o próprio Hillman, a sílaba re é a mais importante, e a mais presente, no trabalho da psicoterapia. Com ela se constroem as principais ações da psicoterapia: relembrar, retornar, rever, refletir, reconhecer, responder, reagir, repetir, remorso, religar, respeitar (p. 128, grifo do autor).

Desse modo, o olhar para o fenômeno seja ele qual for que se apresenta no setting terapêutico, ocupa grande importância, pois a alma se relaciona por imagens, convocando sempre o re, demandado a cada momento.

Jung (1960/1991) destaca que a alma está entre o corpo e a mente. Hillman parte do lugar que a alma ocupa como sendo onde as imagens são geradas e organizadas. É esse o ponto de principal interesse da psicologia arquetípica, que Hillman (1991) considera como uma perspectiva. Assim, o modo de relacionar-se com as coisas é fazer alma, ou seja, observar o fenômeno no qual as imagens se animam no presente momento. Por exemplo: uma pessoa pode reagir de uma forma diante da bandeira do seu país de acordo com o contexto no qual ela se apresenta, porém, a ligação da bandeira como a representação de um coletivo prevalece, sendo essa a alma da bandeira, por esta perspectiva, resgata-se o conceito de anima mundi.

Hillman (2011) discorre sobre o conceito de anima mundi e indica "que todas as coisas são almadas" e devem ser "tratadas com respeito" (p. 47). Fazer alma é olhar para as imagens que são animadas diante do fenômeno de forma metafórica, no momento em que o fenômeno se apresenta, implicando no fato de todos sermos capazes de "fazer alma". Pode-se buscar um exemplo do fazer alma na atitude dos poetas. Por exemplo, um poema de Manuel de Barros (2010) diz:

O rio que fazia uma volta

atrás da nossa casa

era a imagem de um vidro mole...

Passou um homem e disse:

Essa volta que o rio faz...

se chama enseada...

Não era mais a imagem de uma cobra de vidro

que fazia uma volta atrás da casa.

Era uma enseada.

Acho que o nome empobreceu a imagem (p. 303).

Quando lemos "era a imagem de um vidro mole", sabemos o que o poeta quer dizer, contudo, quando a definimos como "uma enseada", a compreendemos pela via do ego e não da alma. Logo, o nome empobrece a imagem, ou seja, voltamos a atenção para a razão e não para a imagem. Fazemos alma quando nos permitimos sentir a frase "era a imagem de um vidro mole". Portanto, quando o psicólogo pede para o paciente relatar um fato, a frase "como se" antes de o paciente narrar o fenômeno, o discurso 
surge em forma de metáfora, significa que imagens estão se fazendo presentes e essas causaram reações nas quais cabe atenção.

Há um paradoxo em relação à alma, no qual é possível ser, ter ou pertencer. Hillman (2010) apresenta algumas possibilidades para alma na psicologia arquetípica:

[...] mas é justamente essa variável interveniente, paradoxal e peculiar que nos dá o sentido de termos ou sermos uma alma [...] comecei a usar o termo de forma razoavelmente livre, frequentemente de forma intercambiável com psique (do grego) e anima (do latim). Agora estou adicionando três modificações necessárias. Primeiro, "alma" refere-se ao aprofundamento dos eventos em experiências; segundo, o significado que a alma torna possível, seja no amor ou nas questões religiosas, deriva-se de sua particular relação com a morte. E, terceiro, por "alma" refiro-me à possibilidade imaginativa em nossa natureza, o experimentar através da especulação reflexiva, do sonho, da imagem e da fantasia - aquele modo que reconhece todas as realidades como primeiramente simbólicas ou metafóricas (p. 27-28, grifos do autor).

A partir dessas possibilidades, compreende-se o fazer alma como uma postura diante daquilo com o qual nos dispomos a nos relacionar, seja uma questão trazida por um paciente ou um objeto de estudo. Neste sentido, pensa-se que a consciência a ser desenvolvida seria vinculada à consciência da alma e não do ego.

Outro conteúdo a ser levado em conta na psicologia arquetípica refere-se à mitologia, por ser um material essencialmente humano, mesmo que se referindo aos deuses. Nas palavras de Hillman (2013):

Os antigos, por assim dizer, não tinham uma psicologia, mas tinham mitos, as narrativas especulativas sobre os humanos em sua relação com as forças e as imagens mais que humanas. Nós, modernos, não temos uma mitologia, por assim dizer, mas temos sistemas psicológicos, as teorias especulativas sobre os humanos em sua relação com as forças e imagens mais que humanas, hoje chamadas campos, instintos, pulsões, complexos (p. 48).

Sabemos da existência de mitos em diversas culturas. Entretanto, não conhecemos sua autoria, no sentido de um autor que assine a história, aspecto que fortalece a ideia da presença arquetípica nos mesmos, principalmente por sua estrutura ser similar a instintos e comportamentos do ser humano. Utilizar de recursos imaginais, tanto em relação a palavras e imagens, nos possibilita uma via de intervenção junto aos conteúdos "obscuros" da alma que possam estar relacionados à queixa de um paciente. 
A psicologia arquetípica cultiva a alma por se permitir metáforas, tanto no cuidado clínico, quanto em seu discurso na pesquisa científica pois, se a linguagem do inconsciente é metafórica propõe-se dialogar com o inconsciente na mesma linguagem. Para Hillman (2010):

A ciência não é sem alma, de forma alguma. Ela também é uma atividade da psique e dos arquétipos na psique, uma das formas de representarmos os deuses. Ao psicologizarmos os problemas, métodos e hipóteses científicos, podemos encontrar suas fantasias arquetípicas. Pois também a ciência é um campo de cultivo da alma, desde que não a encaremos literalmente, em seus próprios termos (p. 323).

Por essa afirmação de Hillman é que talvez se justifique brincar com a etimologia das palavras e re-imaginar mitos sem pedir licença poética.

Após esta breve introdução sobre os conceitos que norteiam a psicologia arquetípica, passa-se a refletir sobre questões concernentes à prática clínica. Compreende-se que o setting terapêutico é permeado por demandas diversas decorrentes do viver. Dentre elas, pode-se mencionar questões sobre a morte e o suicídio, notando-se tratar de um tema extremamente atual, seja por séries como "13 reasons why", lançada no início de 2017, ou por jogos que envolvem riscos para o público adolescente, como o "jogo da baleia" (Moretto et al., 2017). Ideias relativas à morte e ao suicídio do paciente em atendimento podem se fazer presentes no consultório, seja por meio da narração de atos que inconscientemente podem levar o indivíduo à morte por colocá-lo em situações de risco, como também a partir de tentativas concretas de suicídio. $\bigcirc$ psicólogo está muitas vezes frente a temas que são tabus na vida cotidiana e considera-se que o suicídio e a morte em geral se configuram como temas tabus. $\bigcirc$ psicólogo deve ter claro algumas questões pessoais ligadas ao tema suicídio como via de cuidar da questão transferencial e contratransferencial. Neste sentido, encontra-se nas obras de James Hillman um vasto conteúdo que possibilita imaginar e re-imaginar o trabalho terapêutico, inclusive sobre o tema em questão.

Tendo em vista este panorama, esta pesquisa pretendeu debater apontamentos teóricos na perspectiva da psicologia arquetípica, por meio de publicações de James Hillman, para abordagem clínica de questões referentes à morte e ao suicídio. Propõe-se uma investigação da obra de James Hillman relacionando seus apontamentos sobre a prática clínica, com foco na questão do morrer e do suicídio, dentro do que é proposto como atitude do psicólogo, denominado como "fazer alma".

O cultivo da alma ou psicologizar é como um enxergar através, com isso, "o psicologizar enxerga através do que é ensinado; é um aprendizado além de qualquer ensinamento" (Hillman, 2010, p. 264). Por meio do exercício de olhar através, almeja-se olhar para a postura do psicólogo diante do tema suicídio como demanda de acolhimento no cenário clínico. 
Acredita-se que este tipo de proposta se justifica diante dos dados apresentados pela ONU e OMS em relação ao aumento dos índices de suicídio no mundo (Organização das Nações Unidas [ONU], 2017).

psicólogo é um dos profissionais que se dispõe a acolher a demanda ligada ao tema do suicídio, tanto no que diz respeito à pesquisa, quanto ao acolhimento, entendendo-se que a prática do psicólogo deve ser pautada também em conteúdos científicos. Compreende-se que o conteúdo abordado na presente pesquisa pode contribuir para a comunidade acadêmica e para profissionais que norteiam sua prática com base na psicologia arquetípica.

\section{Metodologia}

Trata-se de uma pesquisa qualitativa por almejar uma abordagem "interpretativa e compreensiva dos fenômenos" (Penna, 2007, p. 128). No que se refere às investigações no contexto da psicologia analítica, compreende-se que "o pesquisador participa ativamente do processo de pesquisa interagindo com os aspectos conscientes e inconscientes do fenômeno pesquisado" (Penna, 2007, p. 129). Pensa-se que o conhecimento implica no acesso a elementos inconscientes relacionados à psique coletiva e pessoal, por meio do símbolo que se organiza como uma manifestação do inconsciente na consciência (Penna, 2007). Acredita-se, em consonância com Penna (2007), que o conhecimento é decorrente da possibilidade de acesso ao inconsciente por meio do símbolo.

No que se refere ao percurso metodológico, opta-se por realizar uma pesquisa teórica, por meio da consulta às obras de James Hillman (1984, 1991, 2009, 2010, 2013). Na leitura de "Psicologia Arquetípica", "Suicídio e Alma", "Re-vendo a psicologia", "O mito da análise" e "O sonho e o mundo das trevas", buscou-se estratégias de abordagem quanto aos temas da morte e do suicídio no cenário clínico, voltada para a prevenção e acolhimento do paciente.

\section{Morte e suicídio na psicologia arquetípica}

Dentre tantas palavras imaginadas e pronunciadas num consultório, a palavra morte é uma das que mais carregam tabus sociais, o que demanda ser re-imaginada no setting psicoterapêutico. Segundo Hillman (2013), "extrair significância arquetípica da linguagem da psicologia sugere que a significância já está "lá" nas palavras, suas raízes ou seus sons" (p. 50). Devido a isso, o discurso científico da psicologia arquetípica voltado para a prática clínica expressa, em metáforas, o movimento de aprofundar-se nas questões inconscientes, como uma descida ao mundo de Hades, tido como um submundo (Hillman, 2013). Hades é uma palavra grega que também aparece em algumas traduções da Bíblia, em hebraico, Sheol, referindo-se 
ao lugar dos mortos, a sepultura. Se há assim uma similaridade entre o Hades da mitologia grega e o Sheol, ou inferno, descrito na Bíblia por mais de dez vezes no Antigo Testamento, pode-se dizer que há uma estrutura arquetípica que nos remete ao lugar dos mortos, a um submundo. Tem-se algo que está abaixo, metaforicamente referindo-se ao inconsciente como o mundo de Hades. A partir disso, pensa-se que quando o tema morte surge no setting terapêutico deve-se olhar através do que o discurso diz concretamente, seja um discurso científico ou do paciente. Para isso é importante não confundir silogismo com assimilações metafóricas, ou seja, o exercício imaginal de fazer alma. Não se trata de considerar fatores positivos e negativos para que se chegue em uma posição equilibrada diante da possibilidade de suicídio do indivíduo. Mas sim de possibilitar que o discurso seja metafórico, de modo que se possa estabelecer uma via de escuta ao inconsciente, sendo assim, no presente contexto, o tema morte pode nos convidar ao caminho do inconsciente.

Hades, na mitologia grega não possui representação física, não há imagens, assim também como não há descendência terrestre, nenhum clã ou geração (Hillman, 2013). Se Hades, por assim dizer, não possui forma, mas é pertencente a uma história, isso contribui para ser um tabu, aquilo que não se vê e não se fala. A morte é um tabu social. Sabe-se que ela existe, porém, não a conhecemos, mas temos certeza que um dia a conheceremos. A morte é descrita pela medicina, pela filosofia e pela religião como a única certeza da vida, uma experiência em comum nos seres e singular no indivíduo. Quanto à psicologia analítica, Jung (1971/2000) discorre:

A vida é um processo energético, como qualquer outro, mas, em princípio, todo processo energético é irreversível e, por isto, é orientado univocamente para um objetivo. E este objetivo é o estado de repouso. No fundo, todo processo nada mais é do que, por assim dizer, a perturbação inicial de um estado de repouso perpétuo que procura restabelecer-se sempre. A vida é teleológica par excellence [sic], é a própria persecução de um determinado fim, e o organismo nada mais é do que um sistema de objetivos prefixados que se procura alcançar. $\bigcirc$ termo de cada processo é o seu objetivo. Todo processo energético se assemelha a um corredor que procura alcançar sua meta com o máximo esforço e o maior dispêndio possível de forças (p. 356).

Entende-se, destarte, que a meta da vida é a morte, no que se refere a um ciclo que passa por crescimento, expansão e amadurecimento. No que concerne à psicologia arquetípica, volta-se a atenção às fantasias e desejos do homem em relação à morte como algo necessário a sua natureza e ao processo de individuação (Hillman, 2009).

A morte pode aparecer na clínica de diversas formas: receio, luto, desejo, suicídio, em diversas e imagináveis possibilidades. Quando algo se mostra presente na psique, seja em sonhos, complexos ou eventos de sincronicidade, somatização, ou patologia, significa que precisa ser ouvido. 
A prática clínica embasada na psicologia arquetípica, dispõe-se ao diálogo, nunca a ignorar ou a calar o sintoma. Quando algo se faz presente, e que causando incômodo, acredita-se que trata-se de um tema que estava sendo ignorado de alguma forma. Diferente de práticas que focam no sintoma, a psicologia arquetípica se dispõe a focar no fenômeno, ou seja, ficar com a imagem.

Especificamente em relação ao tema suicídio, pode-se dizer que ele aparece no processo psicoterapêutico, seja declaradamente ou por comportamentos que a ele digam respeito, mesmo que de forma inconsciente ao indivíduo. Segundo Jung (1971/2011):

O impulso inconsciente de suicídio provoca por sua vez uma série de situações imprevistas perigosas, como, por exemplo: uma súbita vertigem em lugar desprotegido, uma hesitação na frente de um automóvel, um engano ao apanhar um vidro de xarope, pegando o de um corrosivo sublimado em seu lugar, uma vontade repentina de fazer acrobacias arriscadas etc. (p. 70).

Observa-se que um movimento em direção à morte é presente no ser humano, dado que nenhum ser humano é eterno (Jung, 1971/2000), que não necessariamente diz respeito a algo de maior ou menor importância. Em resumo, se a força que toma aquela pessoa é de desejo pela morte para além do tido como o processo natural, o que fazer com isso?

Hillman (2009) discorre sobre o suicídio e aponta que "A lei considera-o um crime, a religião chama-o de pecado e a sociedade volta-lhe as costas" ( $p$. 25). A diferença do contexto brasileiro para as considerações de Hillman se dá no que diz respeito ao fato de, no Brasil, o suicídio não ser um crime. Cabe ao psicólogo trabalhar questões consideradas tabus, entre elas o suicídio. Sabe-se da importância do psicólogo também ser submetido à análise para evitar projeções negativas no paciente, tratando-se principalmente de temas que podem ser um tabu social ou pessoal do próprio psicólogo. Sobre esta questão, Hillman (2009) aponta:

Elaborando sua posição em relação ao suicídio, um analista caminha em direção a esse confronto. Isso ajuda-o a aproximar-se da experiência da morte, desenvolvendo sua objetividade e dandothe competência para enfrentá-la psicologicamente, fato comparável à competência médica em relação à morte física ( $p$. 31).

Entrar em contato com a questão do suicídio envolve tanto a pesquisa de diversas áreas sobre o tema, como a sociologia, filosofia, medicina, conhecimento popular, quanto em relação às próprias questões íntimas. Porém, o tema suicídio no processo psicoterapêutico refere-se à singularidade, aos motivos que levam o indivíduo a contar com a possibilidade de cometer suicídio. Trata-se de um caminhar junto ao 
encontro da temática suicídio. O psicólogo deve buscar saber a origem desse desejo, bem como o que o alimenta. Se o trabalho do psicólogo está a serviço da alma, vale buscar o que a alma quer do psicólogo e do paciente em relação ao suicídio ou à morte.

A morte está presente no cotidiano clínico: morrem amores, morrem avós, pais, filhos, amigos. A morte está na vida e quer ser vista. Ignorá-la é tornála mais forte quando ela se faz presente. O suicídio é um chamado da morte que pode ser vivenciado não como algo concreto, mas sim experimentado simbolicamente pela alma. Se a alma nos diz que seu desejo é a morte e este desejo tende à realização concreta, talvez o indivíduo não esteja compreendendo o que a alma quer com essa experiência. De acordo com Hillman (2009):

Quando nos perguntamos por que toda análise defronta-se com a experiência da morte tão frequentemente e em tal variedade, constatamos que, primeiramente, a morte aparece a fim de dar lugar à transformação. A flor murcha em volta de sua haste intumescida, a cobra perde sua pele e o adulto livra-se de suas maneiras infantis. A força criativa mata ao produzir o novo. Cada perturbação e desordem chamada neurose pode ser vista como uma luta de vida e morte, na qual os contendores estão mascarados. $O$ que é chamado de morte pelo neurótico, basicamente porque é escuro e desconhecido, é uma nova vida tentando irromper na consciência; o que ele chama de vida, pelo fato de ser familiar, nada mais é do que um padrão moribundo que ele tenta manter vivo (p. 79, grifos do autor).

Nesse sentido, a psicoterapia vai ao encontro do Hades, que se apresenta similar ao inconsciente, escuro, desconhecido e sem representação concreta. Acolher as demandas da alma, no sentido de se ater ao fenômeno, escutando-a no sentido de compreender e possibilitar a força criativa, para satisfazer o desejo de matar para produzir o novo no exercício de cultivo da alma.

A prática da psicoterapia assume diversas formas devido a variadas justificativas, sejam por motivos de abordagem teórica ou da singularidade de cada psicólogo em sua prática. Em várias obras de James Hillman observam-se críticas aos manuais de psicoterapia e ao discurso técnico da psicologia, bem como aos testes psicológicos ou histórias criadas por teóricos que não consideram a natureza arquetípica, que utilizam de termos técnicos carregados de uma visão patológica dos fenômenos. Para este autor:

Na psicopatologia, a linguagem científica e a fala da alma parecem trilhar caminhos opostos. [...] A linguagem da psicologia insulta a alma. Ela torna infecundas as metáforas transformando-as em abstrações. Adoecemos porque ela está enferma. [...] Ela é financiada pelo governo; faz parte da educação convencional; é a 
primeira coisa à qual se recorre quando uma esposa ou filho se tornam intratáveis. Sua linguagem é moeda corrente, "Material de caso", "desenvolvimento do ego", "psicoterapia" - e mesmo "opressão de animus" e "mãe negativa" - são expressões que morrem em nossos lábios. Não podemos mais acreditar nelas; perderam a convicção; não são mais um discurso impregnado de alma. Esta linguagem está morta (Hillman, 1984, p. 112-113).

Para Hillman (1984), o essencial para a psicoterapia é "desalojar o 'analista interno' que possui uma poltrona em nossa mente. Pois ele também não passa de mais uma fantasia evocada pelo ego" (Hillman, 1984, p. 15). Igualmente, o processo de análise e autoanálise, para que se torne menos nebuloso para o psicólogo em relação ao seu próprio mito.

De acordo com a arte e o estilo individual - que por sua vez deriva do mito individual que cada analista vive - se oferece uma variedade de modelos da prática terapêutica: alguns são sumos sacerdotes do culto da alma, confessores ou guias; outros são pastores de almas, líderes de grupo; há os dialéticos, sofistas, educadores; alguns são pragmáticos, conselheiros práticos, ou biólogos que examinam minuciosamente o histórico de caso; outros são mães nutrientes encorajando $\bigcirc$ crescimento, inspiradoras ou confidentes, enfim, podem ser um mystes, um epoptes, um xamã, um iniciador ou um guru do corpo que desperta sua sensibilidade. A medicina é apenas uma variante, e mesmo os modelos da prática médica variam. Tudo depende, como Jung não se cansava de repetir, da "equação pessoal", e equação pessoal é o mito próprio de cada psicólogo. [...] Descobrir este pattern (padrão) significa procurar nosso patron (patrono), o pai que é o princípio criativo em nós. Esta é a primeira tarefa (Hillman, 1984, p. 23-24, grifos do autor).

Para além do autoconhecimento do psicólogo em saber quem ele é e qual a sua função, há de se levar em conta qual papel ele ocupa para aquele que o procura e como se relaciona com isso. Nas palavras de Hillman (2009):

O único instrumento do analista para intensificar a consciência durante a hora analítica é sua própria pessoa. Por isso, os analistas sempre consideraram a sua própria análise o critério primordial para seu trabalho; os não analisados são leigos (p. 186).

Em relação ao tema do autoconhecimento, pode-se retomar o livro "A prática da psicoterapia", no trecho em que Jung (1971/2011) discorre sobre as cinco etapas da psicoterapia. $\bigcirc$ autor apresenta inicialmente quatro etapas e, ao finalizar o capítulo, complementa-o, apontando para uma quinta etapa. Estas cinco etapas são: confissão, esclarecimento, educação, transformação e autoeducação. 
A primeira etapa refere-se à confissão, vinculada não somente à lembrança de situações, mas também aos afetos presentes no tema. A necessidade de confissão surge devido ao início do segredo que está diretamente ligado ao pecado na humanidade. Ou seja, liga-se a algum comportamento ou atitude que não pode ser exposto e tende a ser recalcado, podendo tornar-se um mistério ou culpa para a consciência, demandando a confissão como necessidade de alívio para o peso da questão.

A segunda etapa relaciona-se ao esclarecimento, que possibilita ao paciente lançar um pouco de luz sobre um lado geralmente escuro da sua alma, bem como ser acolhido pelo psicólogo nesse contato. Para Jung (1971/2011), o momento entre a confissão e o esclarecimento é quando se pode observar a transferência, isto é, qual papel (a partir do paciente) o psicólogo está ocupando no processo. $\bigcirc$ esclarecimento passa a se estabelecer por insights do paciente e (ou) observações do psicólogo.

A terceira etapa vincula-se à educação, que diz respeito à mudança de atitude do paciente, efetuada de forma consciente. Tem-se assim um foco no momento atual, e não no passado. Compreende-se que, mesmo que por algumas vezes seja necessário retomar o passado, pelo fato de muitas neuroses estarem fixadas em alguma situação da infância, o objetivo centrase em possibilitar novos olhares que ainda não se apresentavam como possibilidade para o paciente.

A quarta etapa apresenta-se como a transformação, consequência do processo terapêutico. Neste momento, o paciente torna-se capaz de contar e analisar, a partir de outros olhares, seus comportamentos e anseios, apresentando de forma geral uma mudança de atitude em relação ao início da terapia, assumindo assim outra postura no caminho de conhecer a si mesmo.

A quinta etapa refere-se à autoeducação, que completa todas as outras etapas. Ela tem como parte fundamental a mudança do próprio psicólogo, pois somente o curador ferido pode curar. Envolve sempre relativizar as expectativas em relação ao paciente.

Para Hillman (2011), a alquimia possui o arcabouço para a prática da psicoterapia, considerando que a "linguagem alquímica é um tipo de terapia; ela é, em si, terapêutica" (p. 18). Sendo assim, tal tipo de linguagem se mostra como uma via para discorrer sobre os processos, estágios do trabalho, condições presentes e a relação do psicólogo na psicoterapia. Assim, para atingir a meta na terapia, no sentido alquímico, são necessários alguns passos. Estes passos referem-se a uma questão imaginal, a algo que está além do tempo no qual estamos cientificamente condicionados. Temos com isso, ao invés de procedimentos temporais, um processo mercurial que valoriza as múltiplas possibilidades de cada momento, considerando o processo imaginal (Hillman, 1993). Assim, cada etapa só pode passar para outra se de fato for vivenciada, por exemplo: não se pode cozinhar algum alimento sem antes passar pelo processo do fogo para, então, aquecer a água e finalmente cozinhar. Devido ao fato de o processo terapêutico referir- 
se à relação de elementos diferentes, entende-se que não há como seguir um manual prático, como um livro de receitas. A terapia passa estruturalmente por algumas fases, de modo que a transferência ocorre em todo envolvimento íntimo, sendo necessária para a vida psíquica.

De acordo com Hillman (1984), Jung em seu encontro com Freud, em 1907, aponta para a transferência "como o alfa $(\alpha)$ e o ômega $(\Omega)$ do método analítico" (p. 100), bem como a sua importância dentro deste método. Os fenômenos da transferência possuem uma complexidade alta, principalmente por ser um paradigma arquetípico de toda relação humana. Jung encontrou na alquimia e na mitologia a perspectiva histórica e simbólica para se referir à união de opostos realizada na transferência, bem como a função do amor no fazer alma (Hillman, 1984). Ao considerar o processo alquímico da coniunctio, Hillman (1984) discorre, embasado nos apontamentos de Jung, que o fenômeno da união pode estar ligado tanto à psique quanto a Eros. Neste sentido, Hillman (1984) indica que:

A coniunctio exige amor e alma, que em sua união são um. Sugere ele ainda que a anima desenvolve esta capacidade de união através de quatro estágios da fenomenologia erótica: Eva, Helena (de Tróia), a Virgem Maria e Sofia. Ele as considera como sendo "quatro estágios do culto de Eros" (p. 101, grifos do autor).

Nessa mesma obra (Hillman, 1984), faz outras alusões a fenômenos que já encontramos no mito de Eros e Psique. Por exemplo fala de "gravidez psíquica" e do "filho da alma" em relação ao opus.

A história de Eros permite refletir sobre a psicoterapia na perspectiva da psicologia arquetípica. Eros era filho de Afrodite com Ares, o deus do amor erótico, carnal, tendo sido um grande servo da sua mãe, que também era vingativa e ciumenta. Psique era a filha mais nova de um rei da Grécia antiga que, por ser muito bonita, era venerada com oferendas que antes eram oferecidas a Afrodite. Devido à atenção devotada a Psique, Afrodite ficou irritada com ela e pediu para que Eros fizesse com que Psique se apaixonasse pelo pior dos homens. Porém Eros e Psique acabaram se apaixonando. Com base no mito de Eros e Psique, Hillman (1984) discorre sobre as relações transferenciais e contratransferenciais:

[...] o engendramento da alma através do amor -, então devemos admitir que o que ele traz para o encontro, a assim chamada contratransferência, é realmente anterior à transferência. $\bigcirc$ analista parte de uma posição bem delineada, dada a ele pelo daimon de seu desejo de levar a saúde da consciência, da imaginação e da beleza à vida na alma, ou de constelar, com sua psique, o eros do outro. Não é mais sobre o analista que as projeções são transferidas; ao contrário, através do analista, as intenções do mito da coniunctio são transferidas para o analisando que, desde o início, rebela-se contra estes desígnios do analista. Ele se rebela, se opõe e resiste à missão da psique e do eros do analista. Tudo isto 
forma as assim chamadas "reações de transferência" e "neuroses de transferência" de resistência que, quando não são claramente ligadas a problemas familiares mas se assemelham ao nosso mito, constituem, sem dúvida, o alfa e o ômega do trabalho criativo ( $p$. 102, grifos do autor).

Diante da expectativa anterior ao movimento do daimon, o indivíduo permanece parado na transferência e, nas palavras de Hillman (1984), "Quanto menos o outro puder revelar seu eros, mais exigirei dele; pois de que outra maneira poderia meu processo se inflamar? $O$ meu impulso de individuação, meu desejo de psique deve ser ignizado" (p. 102). Por esse movimento, presente de modo singular com cada paciente, é que não se pode determinar uma sequência lógica ou método comum a todas as relações. Por outro lado, acredita-se que as etapas apresentadas por Jung auxiliam o psicólogo a observar momentos importantes da psicoterapia, pois, como alerta Hillman (1984), a terapia refere-se também a eros e psique. Hillman (2009) chama a atenção para algumas questões que demandam este alerta:

[...] a resistência, a reserva, o silêncio e a suspeita tornam o processo lento. Esses obstáculos mostram-se tão difíceis de serem enfrentados que se deve perguntar por que é que aparecem, se não for precisamente para tornar a transformação mais sólida e duradoura. $\bigcirc$ sigilo, então, cimenta não apenas os laços entre os dois parceiros mas também a integração que ocorre dentro da psique do analisando (p. 194-195).

Na psicologia arquetípica, é preciso ater-se àquilo que se apresenta, tanto em sintomas quanto nas relações, já que os obstáculos que surgem no processo terapêutico também têm algo a comunicar e possuem uma função para o processo.

Devido à relação de transferência e contratransferência, o psicólogo também passa por transformações. Com isso, tende a se permitir aos processos imaginativos do encontro analítico.

Felizmente, como qualquer trabalho criativo, o opus produz seus efeitos no operador, de modo que o analista é transformado pelos contra-efeitos da sua obra, pelos modos como estes o surpreendem. Ele se descobre seu servo, manobrado pelos processos imaginativos do opus, fascinado por sua beleza, um símbolo na história da alma do outro, assim como seu próprio eu é um símbolo na sua, e sente movido pelo daimon do outro (Hillman, 1984, p. 103, grifos do autor).

Quando são observados os efeitos do opus, eles são entendidos como um indicativo de que houve transformações no processo terapêutico.

A meta acerca da qual Hillman (1993) discorre, considerando o sentido alquímico sobre o processo de formação da pérola, se relaciona com o fato 
de um grão de areia apresentar-se como um incômodo necessário para que a pérola possa ser produzida. Ou seja, o sofrimento psíquico pode ser este incômodo necessário ao crescimento e enriquecimento do indivíduo. Destarte, para que haja a transformação, faz-se necessária a descida às profundezas, onde não há luz; entrar em contato com a sombra e os aspectos obscuros da pessoa. Nestas profundezas, pode-se encontrar a ostra ainda hermeticamente fechada, sendo possível mergulhar, capturar a concha e extrair a pérola somente após esse processo. Dá-se sequência, então, a novos cuidados, seja no ato de guardar a joia, seja no procedimento de usála. Tal uso implica no contato da pérola com a pele, contato este que mantém a pérola polida. Sendo assim, o processo terapêutico, no que diz respeito ao tema suicídio, só é possível quando o psicólogo dá conta de permanecer nas profundezas junto ao paciente durante o processo de mudança que se faz necessário a pacientes com este perfil.

\section{Considerações finais}

Não há como prever o conteúdo de uma sessão de psicoterapia, muito menos os rumos que essa pode seguir, desta forma, o psicólogo precisa estar disposto a acolher a demanda que surge em seu trabalho, para que o processo se desenvolva, devendo, ainda, estar disposto à meta da análise.

Entende-se que a prática da psicologia arquetípica só é possível se for por meio de imagens como deuses, alquimia, metáforas, mito, pois para além de uma linguagem universal, entende-se que são essas as formas de expressão da natureza. Discorrer sobre mitos ao tocar no tema do suicídio, como a descida ao Hades ou às profundezas escuras do mar, olhar a psicoterapia como um movimento de encontro com a morte para que haja um novo nascimento, considerar o daimon, apresenta-se de maneira transformadora e nos permite o distanciamento técnico-científico necessário, para o devido cuidado nos casos relacionados ao suicídio. Neste sentido, acredita-se que o psicólogo precisa estudar mitologia, conhecer mitos universais e regionais, estudar os processos alquímicos, estar em processo psicoterapêutico, conhecer os temas míticos que o circundam, recorrer a supervisões. Deve, ademais, questionar-se o porquê do anseio por resultados rápidos e o que são resultados em cada contexto.

As preocupações com a ação, com o procedimento, com o fazer e a técnica são as angústias do animus: com elas estamos numa psicologia do animus. Uma psicologia da anima, ao contrário, permanece na reflexão: a alma e seus reflexos, suas imagens. Permanece na psique, imaginando trabalho e resposta de outra forma. Imaginando terra, esforço e técnica de outra forma: como sabemos, aproximando os procedimentos da psicoterapia dos procedimentos da arte (Barcellos, 2006, p. 133, grifos do autor).

E, por fim, lembrar-se da importância de que quando estiver frente a uma pessoa, o mais importante é permitir-se sentir o que esse encontro quer com 
a alma, para que se possa fazer alma. Quando o psicólogo está identificado com a preocupação externa, seja social ou familiar do paciente, pode tender a assumir a posição médica e científica do tema, por sentir que ele deve salvar o indivíduo da morte, ou seja tirá-lo o mais rápido possível do estado que o mantém ligado ao desejo suicida. Essa atitude distancia o psicólogo da imagem, de modo que o psicólogo é a pessoa que nessa situação deve aguentar junto ao paciente a tensão do desejo pela morte. É necessário, assim, observar quais as fantasias que circundam o desejo pela morte vinda do paciente, notando-se que usualmente são temas sombrios, como raiva, vingança, chantagem, dentre diversas possibilidades.

Por muitas vezes a escuridão assusta. A ausência de luz de um estado depressivo tende a cristalizar, gerando resistência ao sair do estado estático no qual a psique possa estar, mas que, por outro lado, a levou a buscar terapia.

Os textos deixam bem claro que a nigredo não é idêntica à matéria prima, esta um cesto de condições muito maior. A nigredo não é o começo, mas um estágio alcançado. $\bigcirc$ preto é, de fato, uma realização! É uma condição de algo que foi trabalhado, como o carvão é o resultado do fogo atuando numa condição ingênua e natural da madeira, como o fungo escurecido é o resultado da decadência. Embora a depressão, as fixações e obsessões, e um enegrecimento geral do humor e da visão, possam a princípio, trazer uma pessoa para a terapia, essas condições indicam que a alma já está envolvida em sua opus. A iniciação psicológica começou bem antes da primeira hora de terapia. Jung fala da nigredo: "É certo que a opus magnum começa neste ponto" (Hillman, 2011, p. 133-134, grifos do autor).

Pode-se notar que o processo alquímico sempre está ativo. $O$ psicólogo não necessariamente inicia o processo alquímico, mas se dispõe a pertencer ao mesmo. Busca compreender o que a morte deseja nesse encontro para que haja a sua realização transformadora, e não como a concretização no corpo, como almeja o suicida, mesmo que por algumas vezes essa realização ocorra. Pode-se pensar na figura de um carrasco de guilhotina como uma figura humanoide, vestida com um capuz que encobre o seu rosto, mas expõe seus olhos ou alma, como possibilidade de projeções para aqueles que imaginam como é o rosto por debaixo do capuz e o condenado a morte como dono de um espírito negro, condenado. Chegaremos assim à resposta do alquimista ao estado de nigredo.

O que pode liberar a alma de sua identificação sombria? Esta é a questão colocada em cada análise, e também colocada durante os momentos de nigredo da vida. A resposta do alquimista: decapitação. De acordo com Jung, o espírito negro deve ser degolado, um ato que separa a compreensão de sua identificação com o sofrimento. Porque "na nigredo o cérebro se obscurece", a decapitação "emancipa a cogitatio". O negror permanece, mas a 
distinção entre cabeça e corpo cria um "dois", enquanto que o sofrimento nos aprisiona na singularidade, no único. A mente pode começar a reconhecer aquilo que o corpo só sente. A decapitação permite que a mente liberte-se [sic] da identificação com o corpo (Hillman, 2011, p. 141, grifos do autor).

A decapitação refere-se somente ao estado de nigredo, em casos nos quais a cabeça está colocada de modo fraco, ou seja, não reconhece ou sente o corpo ao qual ela pertence, de modo insensível ao corpo. O corpo é associado ao concretismo das questões do paciente, por exemplo, quando o indivíduo entende a morte concreta como única saída para estado no qual se encontra.

Mais uma vez, tocam-se em figuras ligadas à morte para falar do processo psicoterapêutico, sendo esse o lugar também de acolhimento para o desejo de morte. Enquanto figuras como a do carrasco, a cor escura, o suicídio forem consideradas concretamente e não imageticamente, levando o psicólogo a sentir repulsa pelo tema, mais difícil será para o profissional dar conta da demanda do suicídio, pois diz respeito à dificuldade em permitir-se imaginar, no sentido de fazer alma.

\section{Referências}

Adams, M. V. (2002). A escola arquetípica. In P. Young-Eisendrath, \& T. Dawson (Orgs.), Manual de Cambridge para estudos junguianos (pp. $111-$ 125). Porto Alegre: Artmed Editora.

Barcellos, G. (2006). Vôos \& raízes. São Paulo: Ágora.

Barros, M. (2010). Poesia completa. São Paulo: Leya.

Hillman, J. (1984). O mito da análise: três ensaios de psicologia arquetípica. Rio de Janeiro: Paz e Terra.

Hillman, J. (1991). Psicologia arquetípica: um breve relato. São Paulo: Cultrix.

Hillman, J. (1993). Concerning the Stone: Alchemical Images of the Goal.

Sphinx 5. London: Convivium for Archetypal Studies.

Hillman, J. (2009). Suicídio e alma. Petrópolis, RJ: Vozes.

Hillman, J. (2010). Re-vendo a psicologia. Petrópolis, RJ: Vozes.

Hillman, J. (201 1). Psicologia alquímica. Petrópolis, RJ: Vozes.

Hillman, J. (2013). O sonho e o mundo das trevas. Petrópolis, RJ: Vozes.

Jung, C. G. (1991). Tipos psicológicos. Petrópolis: Vozes. (Trabalho original publicado em 1960).

Jung, C.G. (2000). A alma e a morte. In A natureza da Psique. Petrópolis:

Vozes. (Trabalho original publicado em 1971).

Jung, C.G. (2002). Os arquétipos e o inconsciente coletivo. Petrópolis: Vozes.

(Trabalho original publicado em 1976). 
Jung, C.G. (2011). A prática da psicoterapia: contribuições ao problema da psicoterapia e à psicologia da transferência. Petrópolis: Vozes. (Trabalho original publicado em 1971).

Moretto, M. L. T., Svartman, B. P., Freller, C. C., Massola, G. M., Crochík, J. L., \& Silva, P. F. (2017). O suicídio e a morte do narrador. Psicologia USP, 28(2), 159-164. http://dx.doi.org/10.1590/0103-656420172802.

Organização das Nações Unidas. (2017). Campanha da ONU busca conscientizar população sobre prevenção ao suicídio. Recuperado em 05 agosto 2018, de https://nacoesunidas.org/campanha-da-onu-buscaconscientizar-populacao-sobre-prevencao-ao-suicidio/

Penna, E. M. D. (2007). Pesquisa em psicologia analítica: reflexões sobre o inconsciente do pesquisador. Boletim de Psicologia, 57(127), 127-138. Recuperado em 05 agosto 2018, de http://pepsic.bvsalud.org/scielo.php?script=sci_arttext\&pid=S000659432007000200002

Samuels, A. (1988). Dicionário crítico de análise junguiana. Rio de Janeiro: Imago.

Samuels, A. (1989). Jung e os pós-junguianos. Rio de Janeiro: Imago.

Sant'Anna, P. A. (2001). As imagens no contexto clínico de abordagem junguiana: uma interlocução entre teoria e prática. Tese de Doutorado. Instituto de Psicologia, Universidade de São Paulo, São Paulo.

Minicurrículos: Helton Marculino de Souza - Psicólogo. Eespecialista em Saúde Mental pela Universidade Estadual de Londrina (UEL). Especializando em Psicologia Analítica Junguiana pela Universidade Estadual de Campinas (UNICAMP).

E-mail: helton.marculino@gmail.com

Lunalva Fiuza Chagas - Psicóloga. Especialista em Psicologia Clínica, analista didata e membro do Instituto de Psicologia Analítica de Campinas (IPAC), da Associação Junguiana do Brasil (AJB), e da International Association for Analytical Psychology (IAAP). Docente convidada no Curso de Especialização em Psicologia Analítica da Universidade Estadual de Campinas (UNICAMP). E-mail: lunalvafchagas@terra.com.br 